\title{
SYNTHESIS OF CURCUMIN FROM PIPERONAL AND ITS SPECTROMETRIC CHARACTERIZATION USING DFT- B3LYP/6-31G(d) METHOD
}

\author{
M. R. Sohilait ${ }^{1, \bowtie}$, H. D. Pranowo ${ }^{2}$ and W. Haryadi ${ }^{2}$ \\ ${ }^{1}$ Department of Chemistry, Faculty of Mathematics and Natural Sciences, Universitas Pattimura, \\ 97233, Maluku, Indonesia \\ ${ }^{2}$ Department of Chemistry, Faculty of Mathematics and Natural Sciences, Universitas Gadjah \\ Mada, 55281, Yogyakarta, Indonesia \\ Corresponding Author: rio.rowan@gmail.com
}

\begin{abstract}
Synthesis of curcumin analog of 1,5-bis(1,3-benzodioxol-5yl)penta-1,4-dien-3-one via condensation reaction between piperonal and acetone in ethanol has been performed. The product was characterized using LC, MS, FT-IR, ${ }^{1} \mathrm{H}$ and ${ }^{13} \mathrm{C}$-NMR spectrometers. The product was obtained as pale-yellow solid in $94.87 \%$ yield and purity of $100 \%$. Then, the spectroscopic characterization of the analog was conducted using Gaussian'09 with the method of DFTB3LYP/6-31G(d). It was shown that the method gave similar IR vibration, ${ }^{1} \mathrm{H}$ and ${ }^{13} \mathrm{C}-\mathrm{NMR}$ spectra as those of experimental results.

Keywords: Curcumin Analog, Piperonal, DFT-B3LYP/6-31G(d).
\end{abstract}

RASĀYAN J. Chem., Vol. 14, No.2, 2021

\section{INTRODUCTION}

The research on the field of curcumin has obtained more attention due to its biological activities, such as anti-oxidant ${ }^{1-3}$, anti-tumour ${ }^{3}$, anti-cancer agents ${ }^{3}$, anti-inflammatory ${ }^{4-5}$, and anti-microbial. The activity and stability of the parent compound can be improved by modifying the side chain of the aromatic ring pharmacophore with asymmetric or symmetric substituents and the dienone functional group to monocetone. ${ }^{6}$ Research by Robinson et al. showed that the activity of curcumin analogs as anticancer is better in the presence of changes in the structure of $\alpha, \beta$ unsaturated ketones to $\beta$ dicetone. This proves that these structural changes provide better activity than curcumin itself. ${ }^{7}$

Computational chemistry could be precisely employed to elucidate the chemical structure. It may predict the infrared, raman ${ }^{8-9}$, UV-Vis ${ }^{10}$, and NMR. ${ }^{9}$ Density Functional Theory (DFT) has been well developed during the last decade as the effective method in the chemical simulation ${ }^{11}$. This theory has based on the energy of the electronic system which might be defined as the equation of the electron probability density, $\rho$. For the system with the $\mathrm{n}$ electron, $\rho(\mathrm{r})$ described the total electron density in a certain scope, $r$. Based on the formalism of DFT, electronic energy was considered as the function of electron density E[ $\rho]$, at which the function of $\rho(\mathrm{r})$ related to the single energy. For instance, one correspondent between the electron density on the system and its energy. The results obtained from DFT were varied and depended on the choice of basis set. Recently, B3LYP is the commonly used method. ${ }^{12}$

\section{EXPERIMENTAL}

\section{Materials}

The materials employed in the synthesis were piperonal, acetone, methanol, ethanol, and potassium hydroxide. All the chemicals were purchased from E. Merck with pure analysis grade.

\section{Instrumentation}

The tools used for the structure elucidation were HPLC (LC-20AD Prominence, Shimadzu), FTIR (Shimadzu FTIR Prestige 21), MS DirecT Inlet (MS, Shimadzu QP2010S), ${ }^{1} \mathrm{H}$ and ${ }^{13} \mathrm{C}-\mathrm{NMR}$ spectrometers (NMR JEOL JNM ECA $500 \mathrm{MHz}$ ). 
RASĀYAN J. Chem.

Vol. 14 | No. 2 |1307-1311| April - June | 2021

The software utilized was Gaussian $09 \mathrm{~W}$ as well as the set of computers with the specification of the processor of Intel ${ }^{\circledR}$ Core $^{\mathrm{TM}}$ i5- 3317U CPU @ 1,70 GHz, RAM 4 GB, and hard disk of 500 GB.

\section{Synthesis of 1,5-bis(1,3-benzodioxol-5yl)penta-1,4-dien-3-one from Piperonal and Acetone}

As much as $3.0 \mathrm{~g}(0.02 \mathrm{~mol})$ of piperonal was placed in the $125 \mathrm{~mL}$ of round-bottomed-flask. Acetone $(0.58 \mathrm{~g}, 0.01 \mathrm{~mol})$ and ethanol $(30 \mathrm{~mL})$ were then added. The solution was stirred for $20 \mathrm{~min}$. Then, 0.65 $\mathrm{g}(0.01 \mathrm{~mol})$ of $\mathrm{KOH}$ was added and the mixture was stirred at room temperature for $6 \mathrm{~h}$ until the formation of solid. The solid was filtered, washed with aquadest and cold ethanol. The solid was recrystallized from ethanol. The product was elucidated by using LC, IR, MS, ${ }^{1} \mathrm{H}$ and ${ }^{13} \mathrm{C}-\mathrm{NMR}$ spectrometers.

\section{Spectroscopic Characterization of 1,5-bis(1,3-benzodioxol-5yl)penta-1,4-dien-3-one using DFT- B3LYP/6-31G(d) Method}

The 3D structure compound was drawn and saved (*.PDB). Geometry optimization was conducted using the program of Gaussian'09 with the method of DFT-B3LYP and the basis set of 6-31G(d). It was aimed to obtain the structure with the minimum surface potential energy and well-defined structure. The computational calculation included geometry optimization, frequency, NMR calculation. The obtained IR, NMR spectra from the calculation were compared with the experimental results.

\section{RESULTS AND DISCUSSION}

\section{Synthesis of 1,5-bis(1,3-benzodioxol-5yl)penta-1,4-dien-3-one from Piperonal and Acetone}

The compound of 1,5-bis(1,3-benzodioxol-5yl)penta-1,4-dien-3-one was obtained as the pale yellow solid with the m.p. of 199.8 in $94.87 \%$ yield. The LC analysis (Fig.-1) that the purity of the product was $100 \%$ (retention time of $3.385 \mathrm{~min}$ ). The mass spectrum (Fig.-2) gave several peaks at $\mathrm{m} / \mathrm{z}$ of 32, 51, 63, 76, 89 (base peak), 103, 117, 135, 145, 160, 175, 189, 200, 217, 235, 247, 264, 293, 321 and $322\left[\mathrm{C}_{19} \mathrm{H}_{14} \mathrm{O}_{5}\right]^{+}$. The mass spectrum showed that the molecular mass of the product was $322 \mathrm{~g} / \mathrm{mol}$ which was in full agreement with the mass of 1,5-bis(1,3-benzodioxol-5yl)penta-1,4-dien-3-one. The IR spectrum (Fig.-3) showed the absorption at $1643 \mathrm{~cm}^{-1}$ from the carbonyl $(\mathrm{C}=\mathrm{O})$ group. Additionally, the peaks at 1581 and $1496 \mathrm{~cm}^{-1}$ represented the stretching of aromatic $\mathrm{C}=\mathrm{C}$ and aliphatic $\mathrm{C}=\mathrm{C}$ bonds, respectively. It was strengthened by the appearance of the peak at $1257 \mathrm{~cm}^{-1}$ from the methylenedioxy $\left(\mathrm{OCH}_{2} \mathrm{O}\right)$ group.

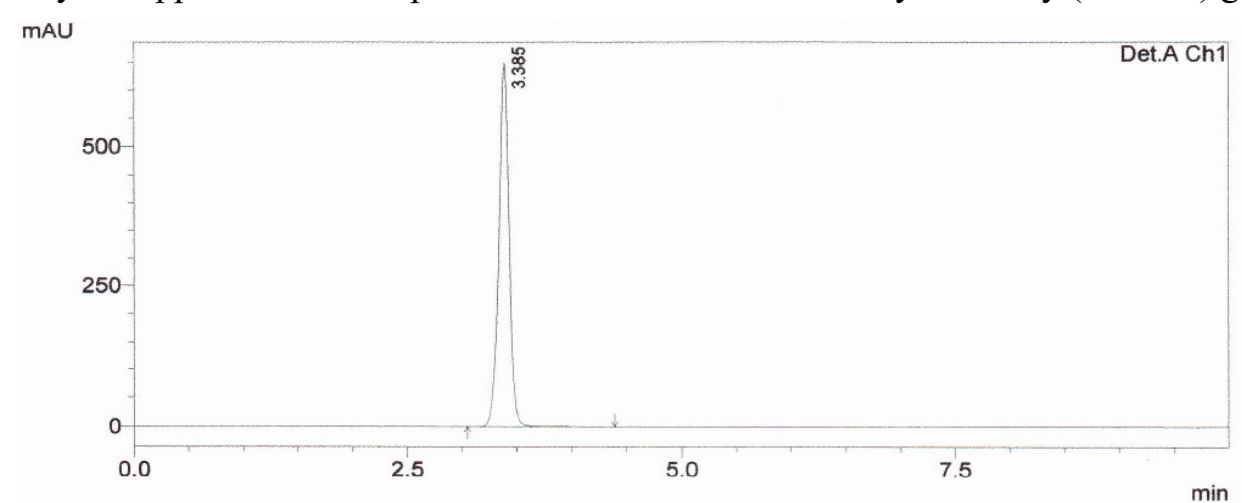

Fig.-1: Chromatogram of 1,5-bis(1,3-benzodioxol-5yl)penta-1,4-dien-3-one

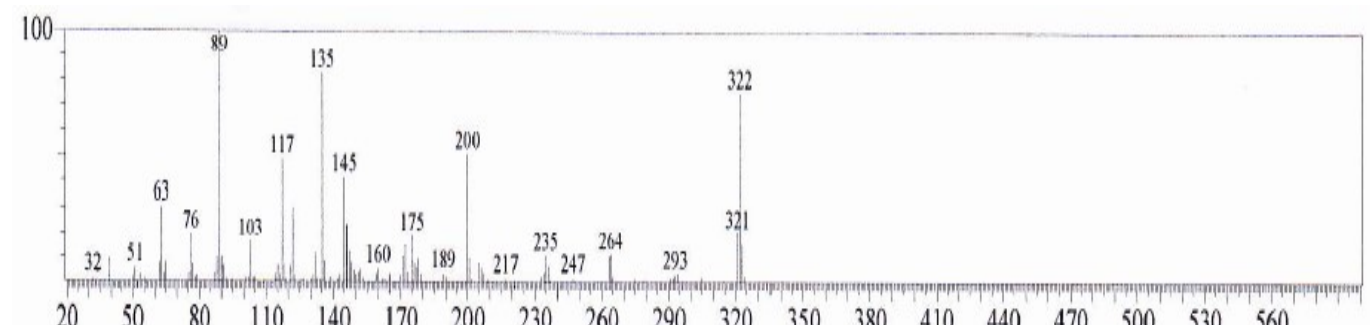

Fig.-2: Mass spectrum of 1,5-bis(1,3-benzodioxol-5yl)penta-1,4-dien-3-one

\section{8}


RASĀYAN J. Chem.

Vol. 14 | No. 2 |1307-1311| April - June | 2021

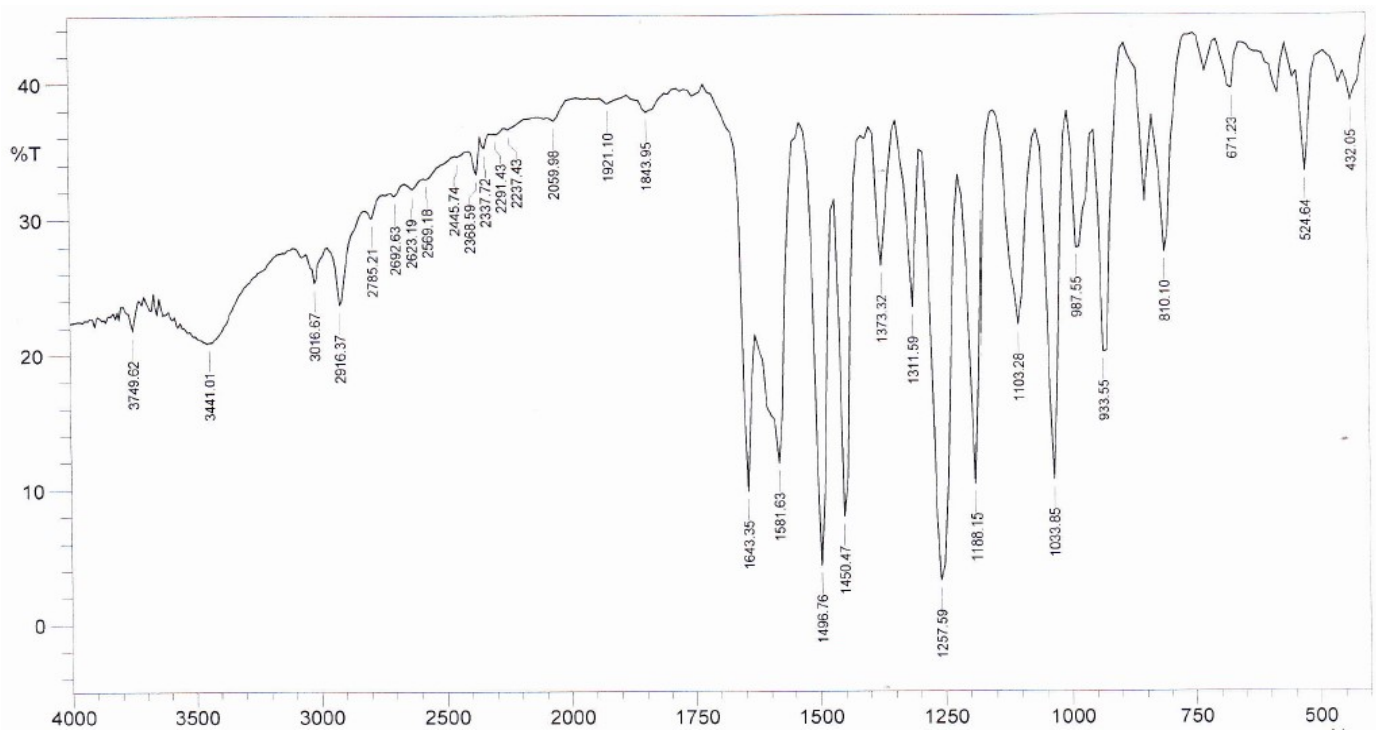

Fig.-3: IR spectrum of 1,5-bis(1,3-benzodioxol-5yl)penta-1,4-dien-3-one

Further analysis using a ${ }^{1} \mathrm{H}-\mathrm{NMR}$ spectrometer (Fig.-4, $500 \mathrm{MHz}$ in DMSO-D6) gave 6 peaks depicted the 6 protons with different chemical environments. There were signals $\mathrm{A}\left(\delta=6.1 \mathrm{ppm}, \mathrm{s}, 4 \mathrm{H}, \mathrm{OC}_{2} \mathrm{O}-\right)$, $\mathrm{B}\left(\delta=7.0 \mathrm{ppm}, \mathrm{d}, J=7.8 \mathrm{~Hz}, 2 \mathrm{H}, \mathrm{H}^{5}, \mathrm{H}^{5} \mathrm{Ar}\right), \mathrm{C}(\delta=7.1 \mathrm{ppm}, \mathrm{d}, J=16.2 \mathrm{~Hz}, 2 \mathrm{H},=\mathrm{C} \underline{\mathrm{H}}-\mathrm{C}=\mathrm{O}), \mathrm{D}(\delta=7.2 \mathrm{ppm}$, $\left.\mathrm{d}, J=7.8 \mathrm{~Hz}, 2 \mathrm{H}, d, \mathrm{H}^{6}, \mathrm{H}^{6} \mathrm{Ar}\right), \mathrm{E}\left(\delta=7.4 \mathrm{ppm}, \mathrm{s}, 2 \mathrm{H}, \mathrm{H}^{2}, \mathrm{H}^{2}\right.$ Ar) and $\mathrm{F}(\delta=7.6 \mathrm{ppm}, \mathrm{d}, J=16.2 \mathrm{~Hz}, 1 \mathrm{H}, \mathrm{Ar}-$ $\mathrm{C} \underline{\mathrm{H}}=\mathrm{CH})$. The ${ }^{13} \mathrm{C}-\mathrm{NMR}$ spectrum (Fig.-5) gave several peaks with the chemical shifts of $101.6(2 \mathrm{x}-$ $\left.\mathrm{OCH}_{2} \mathrm{O}-\right), 106.6\left(\mathrm{C}^{2}, \mathrm{C}^{2} \mathrm{Ar}\right), 108.6\left(\mathrm{C}^{5}, \mathrm{C}^{5} \mathrm{Ar}\right), 123.9\left(\mathrm{C}^{6}, \mathrm{C}^{6} \mathrm{Ar}\right), 125.2\left(\mathrm{C}^{1}, \mathrm{C}^{1} \mathrm{Ar}\right), 129.2(=\mathrm{CH}-\mathrm{C}=\mathrm{O})$, $142.3\left(\mathrm{C}^{4}, \mathrm{C}^{4} \mathrm{Ar}\right), 148.0\left(\mathrm{C}^{3}, \mathrm{C}^{3} \mathrm{Ar}\right), 149.4(\mathrm{Ar}-\mathrm{CH}=)$ and $188.2(\mathrm{C}=\mathrm{O}) \mathrm{ppm}$. The proposed mechanism of the condensation reaction between acetone and piperonal was presented in Fig.- 6 .

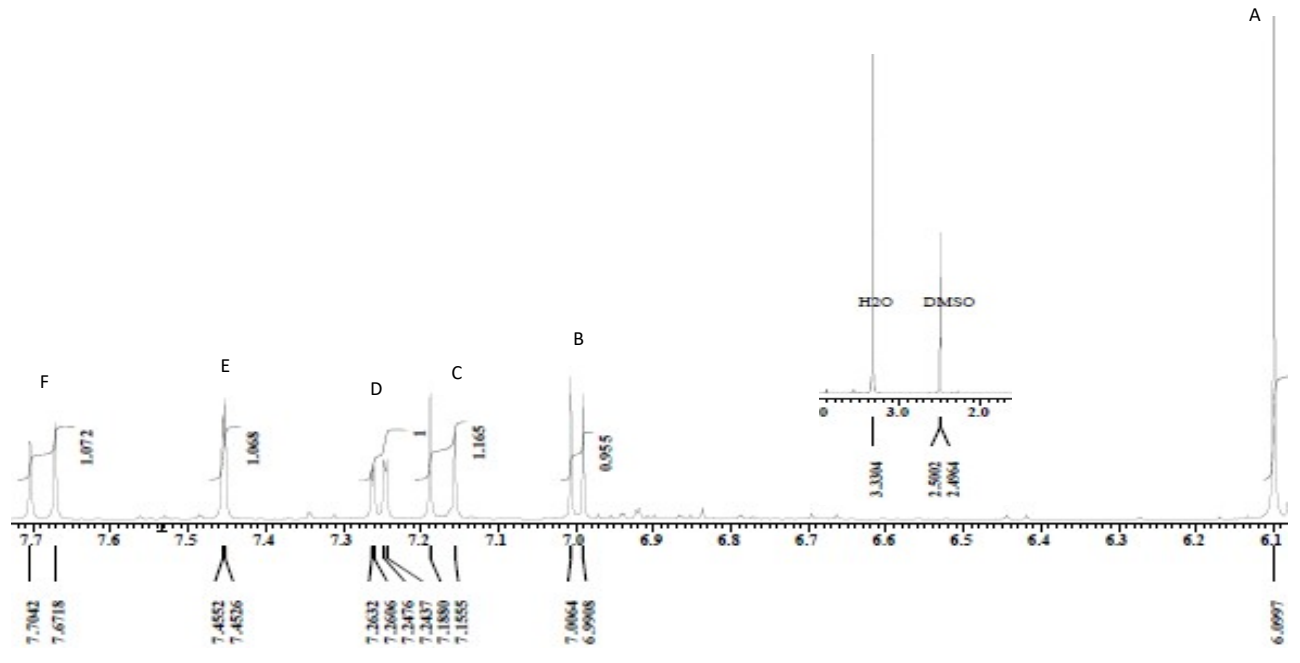

Fig.-4: ${ }^{1}$ H-NMR Spectrum of 1,5-bis(1,3-benzodioxol-5yl)penta-1,4-dien-3-one

Spectroscopic Characterization of 1,5-bis(1,3-benzodioxol-5yl)penta-1,4-dien-3-one using DFTB3LYP/6-31G(d) Method

The optimized structure of 1,5-bis(1,3-benzodioxol-5yl)penta-1,4-dien-3-one had the lower energy level of -1108.50033699 a.u. with the RMS gradient of 0.00000091 a.u. The prediction of the IR spectrum 
RASĀYAN J. Chem.

Vol. 14 | No. 2 |1307-1311| April - June | 2021

could be seen in Table-1. It was shown that the differences between the experimental and the computational spectrum were low. The differences might be due to the geometry optimization have not given the same structure of the product as in nature yet. Both calculated ${ }^{1} \mathrm{H}$ and ${ }^{13} \mathrm{C}$-NMR spectra could be observed in Table- 2 and Table-3. Similarly, the differences between the experimental and calculated results were low. The calculation was conducted without considering the presence of the solvent, thus it gave a few differences.

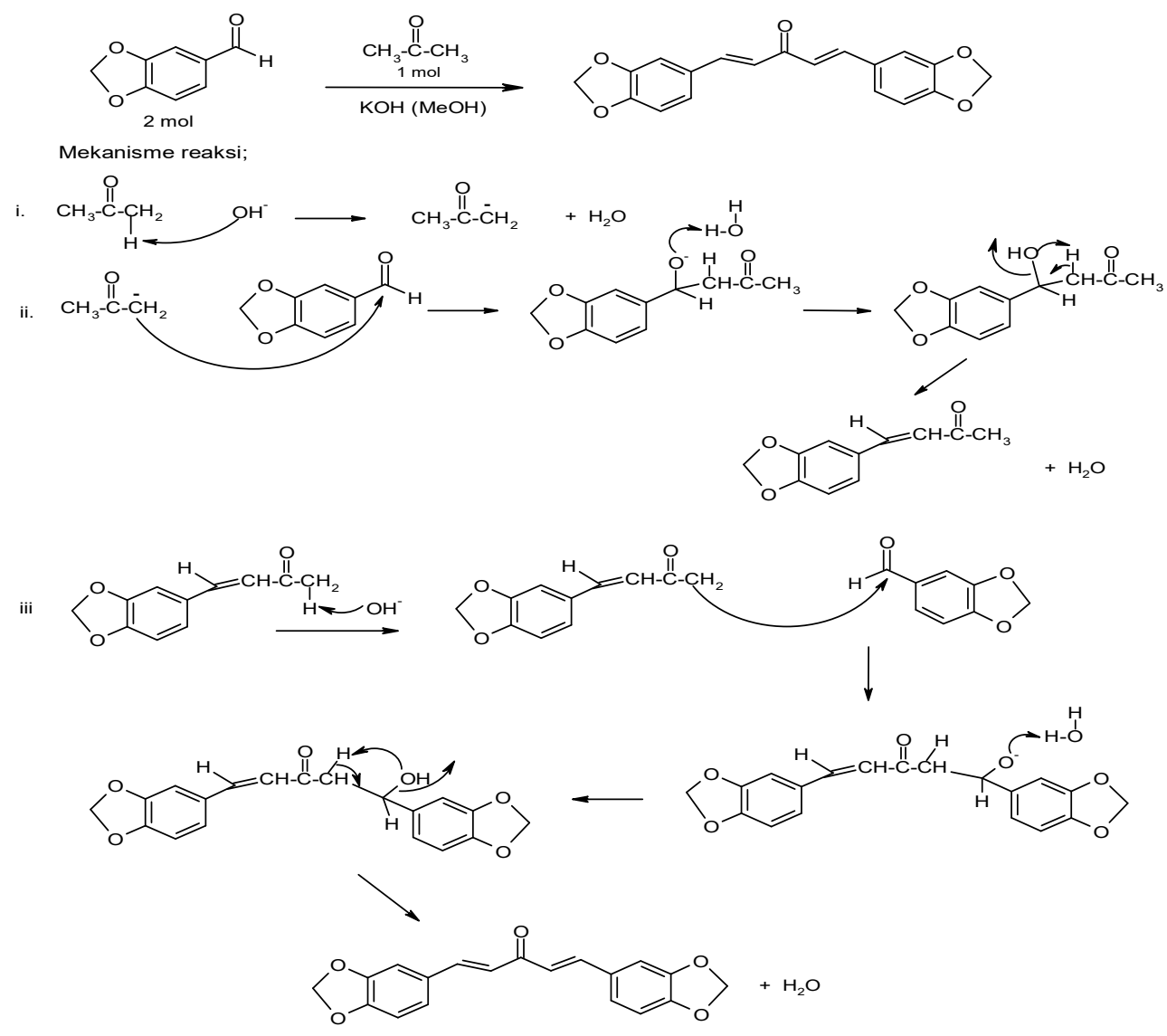

Fig.-6: Mechanism of the Synthesis of 1,5-bis(1,3-benzodioxol-5yl)penta-1,4-dien-3-one

Table-1: IR Spectrum of 1,5-bis(1,3-benzodioxol-5yl)penta-1,4-dien-3-one

\begin{tabular}{c|c|c}
\hline Functional Group & Experiment $\left(\mathrm{cm}^{-1}\right)$ & DFT-B3LYP/6-31G(d) $\left(\mathrm{cm}^{-1}\right)$ \\
\hline $\mathrm{C}=\mathrm{O}$ & 1643.35 & 1636.71 \\
\hline $\mathrm{C}=\mathrm{C}$ aromatic & 1581.63 & 1542.28 \\
\hline $\mathrm{C}=\mathrm{C}$ aliphatic & 1496.76 & 1404.36 \\
\hline $\mathrm{OCH}_{2}$ & 1257.59 & 1291.43 \\
\hline
\end{tabular}

Table-2: ${ }^{1} \mathrm{H}-\mathrm{NMR}$ Spectrum of 1,5-bis(1,3-benzodioxol-5yl)penta-1,4-dien-3-one

\begin{tabular}{c|c|c}
\hline Information & $\begin{array}{c}\text { Experiment } \\
(\mathrm{ppm})\end{array}$ & $\begin{array}{c}\text { DFT-B3LYP/6-31G(d) } \\
(\mathrm{ppm})\end{array}$ \\
\hline $\mathrm{s}, \mathrm{OCH}_{2} \mathrm{O}, 4 \mathrm{H}$ & 6.1 & 6.1 \\
\hline $\mathrm{d}, \mathrm{H}^{5}, \mathrm{H}^{5} \mathrm{Ar}$ & 7.0 & 6.3 \\
\hline $\mathrm{d},=\mathrm{CH}-\mathrm{C}=\mathrm{O}, 2 \mathrm{H}$ & 7.1 & 6.4 \\
\hline $\mathrm{d}, \mathrm{H}^{6}, \mathrm{H}^{6} \mathrm{Ar}$ & 7.2 & 6.7 \\
\hline $\mathrm{s}, \mathrm{H}^{2}, \mathrm{H}^{2} \mathrm{Ar}$ & 7.4 & 7.4 \\
\hline $\mathrm{d}, \mathrm{Ar}-\mathrm{C} \underline{\mathrm{H}}=\mathrm{CH}$ & 7.6 & 7,6 \\
\hline
\end{tabular}


RASĀYAN J. Chem.

Vol. 14 | No. 2 |1307-1311| April - June | 2021

Table-3: ${ }^{13} \mathrm{C}-\mathrm{NMR}$ Spectrum of 1,5-bis(1,3-benzodioxol-5yl)penta-1,4-dien-3-one

\begin{tabular}{c|c|c}
\hline Information & Experiment $(\mathrm{ppm})$ & DFT-B3LYP/6-31G(d) $(\mathrm{ppm})$ \\
\hline $2 \mathrm{x}-\mathrm{OCH}_{2} \mathrm{O}$ & 101.6 & 96.2 \\
\hline $\mathrm{C}^{2}, \mathrm{C}^{2} \mathrm{Ar}$ & 106.6 & 96.9 \\
$\mathrm{C}^{5}, \mathrm{C}^{5} \mathrm{Ar}$ & 108.6 & 97.8 \\
$\mathrm{C}^{6}, \mathrm{C}^{6} \mathrm{Ar}$ & 123.9 & 104.6 \\
$\mathrm{C}^{1}, \mathrm{C}^{1} \mathrm{Ar}$ & 125.2 & 111.7 \\
\hline$=\mathrm{CH}-\mathrm{C}=\mathrm{O}$ & 129.2 & 114.1 \\
\hline $\mathrm{C}^{4}, \mathrm{C}^{4} \mathrm{Ar}$ & 142.3 & 128.3 \\
\hline $\mathrm{C}^{3}, \mathrm{C}^{3} \mathrm{Ar}$ & 148.0 & 128.8 \\
\hline $\mathrm{Ar}-\mathrm{CH}=\mathrm{CH}$ & 149.4 & 131.9 \\
\hline $\mathrm{C}=\mathrm{O}$ & 188.2 & 160.2 \\
\hline
\end{tabular}

\section{CONCLUSION}

The curcumin analog of 1,5-bis(1,3-benzodioxol-5yl)penta-1,4-dien-3-one could be synthesized from piperonal and acetone via condensation reaction with a yield of $94.87 \%$ and purity of $100 \%$. Spectroscopic characterization of the analog using Gaussian'09 with DFT-B3LYP/6-31G(d) method gave similar IR vibration, ${ }^{1} \mathrm{H}$ and ${ }^{13} \mathrm{C}-\mathrm{NMR}$ spectra as those of experimental results.

\section{REFERENCES}

1. K. Jakubczyk, A. Druzga, J. Katarzyna and K. Skonieczna-Zydecka, Antioxidants, 9, 1092(2020), DOI: 10.3390/antiox9111092

2. S. Atun, Y. Dewi and N. Aznam, Rasayan Journal of Chemistry, 13(2), 817(2020), DOI: $10.31788 /$ RJC.2020.1325680

3. P. Anand, S.G. Thomas, A.B. Kunnumakkara, C. Sundaram, K.B. Harikumar, B. Sung, S.T. Tharakan, K. Misra, I.K. Priyadarsini, K.N. Rajasekharan and B.B. Aggarwal, Biochemical Pharmacology, 76, 1590(2008), DOI:10.1016/j.bcp.2008.08.008

4. M.R. Sohilait, H.D. Pranowo and W. Haryadi, Asian Journal of Chemistry, 30, 1765(2018), DOI:10.14233/ajchem.2018.21297

5. M.R. Sohilait, H.D. Pranowo and W. Haryadi, Bioinformation, 13, 356(2017), DOI:10.6026/97320630013356

6. B.K. Adams, E.M. Ferstl, M.C. Davis, M. Herold, S. Kurtkaya, R.F. Camalier, M.G. Hollingshead, G. Kaur, E.A Sausville, F.R. Rickles, Snyder, J.P., D.C. Liotta and M. Shoji, Bioorganic and Medicinal Chemistry, 12, 3871(2004), DOI:10.1016/j.bmc.2004.05.006

7. K.M. Youssef, M.A. El-Sherbeny, F.S. El-Shafie, H.A. Farag, O.A. Al-Deeb and S.A.A. Awadalla, Archiv der Pharmazie, 337, 42(2004), DOI:10.1002/ardp.200300763

8. T.P. Robinson, R.B. Hubbard, IV, T.J. Ehlers, J.L. Arbiser, D.J. Goldsmith and J.P. Bowen, Bioorganic and Medicinal Chemistry, 13, 4007(2005), DOI:10.1016/j.bmc.2005.03.054

9. M. Talu, E.U. Demiroglu, S. Yurdakul and S. Badoglu, Spectrochimica Acta Part A: Molecular and Biomolecular Spectroscopy, 134, 267(2015), DOI:10.1016/j.saa.2014.06.101

10. N. Subramanian, N. Sundaraganesan and J. Jayabharathi, Spectrochimica Acta Part A: Molecular and Biomolecular Spectroscopy, 76, 259(2010), DOI:10.1016/j.saa.2010.03.033

11. P. Deng, H.D. Zhang, J. Jiang and Q.H. Jiang, The Journal of Atomic and Molecular Sciences, 2 , 51(2011), DOI:10.4208/jams.081910.092010a

12. S.F. Soussa, P.A. Fernandes and M.J. Ramos, The Journal of Physical Chemistry A, 111, 10439(2007), DOI:10.1021/jp0734474

[RJC-6148/2020] 